\title{
Problematizando discursos educacionais críticos em Meu professor é o cara*
}

\author{
Problematising critical educational discourses in Meu professor é o cara
}

\author{
Ana Paula Quevedo Peila \\ Angela Dillmann Nunes Bicca ${ }^{b}$
}

\section{Editores}

Maria Inês Côrte Vitoria PUCRS, RS, Brasil

Pricila Kohls dos Santos PUCRS, RS, Brasil

\section{Equipe Editorial}

Carla Spagnolo

PUCRS, Brasil

Rosa Maria Rigo

PUCRS, Brasil

\section{ISSN 2179-8435}

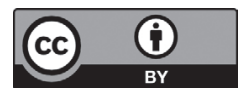

Este artigo está licenciado sob forma de uma licença Creative Commons Atribuição 4.0 Internacional, qu qualquer meio, desde que a publicaçăo original seja corretamente citada. http://creativecommons.org/licenses/by/4.0/deed.pt_BP

\section{RESUMO}

A mídia educativa vem acionando discursos educacionais que têm colaborado para a produção de docentes de determinados tipos. Atentando para tal atuação, inseridas nos estudos culturais de inspiração pós-estruturalista, objetivou-se problematizar alguns elementos desses discursos educacionais acionados de forma recorrente no quadro Meu professor é o cara, integrante do programa de televisão Como será? da Rede Globo de Televisão. Os episódios analisados indicam que os/as professores/as destacados/as procuraram afastar-se ao máximo do qualificado como ensino tradicional, valorizando aspectos dos discursos educacionais críticos e enfatizando que a aprendizagem se efetiva a partir da reconfiguração do espaço de sala de aula e de investimentos na afetividade. O que proporciona uma prática considerada diferenciada.

Palavras-chave: Discursos educacionais; Mídia educativa; Programa de TV

\section{ABSTRACT}

The educational media has used educational discourses helping to produce particular types of teachers. Focusing on that use and belonging to the poststructuralist Cultural Studies, we aim to problematise some elements in these educational discourses recurrent in the attraction Meu professor é o cara in the television show Como será? presented in the TV channel Globo. The analysed episodes showed that the teachers sought to avoid the traditional teaching, by valuing aspects in the critical educational discourses, stressing that learning is successful when the classroom space is reshaped and when there is investment in affectivity, providing practice considered distinguished. Keywords: Educational discourses; Educational media; TV programme

\footnotetext{
* Quadro integrante do programa de TV denominado Como será?, que foi ao ar de 9 de agosto de 2014 a 28 de março de 2015 , totalizando 29 episódios.

a Professora do Instituto Federal Sul-rio-grandense IFSUL. Tecnóloga em Gestão Ambiental, Especialista em Educação Profissional, Mestre em Educação.

b Professora do Instituto Federal Sul-rio-grandense IFSUL. Licenciada em Física e Especialista em Lógica e Filosofia da Ciência (UCPel),
} Mestre e Doutora em Educação (UFRGS). 


\section{Introdução}

$\mathrm{s}$ abordagens pedagógicas que se alinham à vertente crítica constituem-se em importantes discursos educacionais acionados de forma recorrente no quadro Meu professor é o cara ${ }^{1}$, integrante do programa de televisão denominado Como será? da Rede Globo de Televisão. Ao produzir e fazer circular discursos educacionais, o programa contribui para posicionar professores e professoras como aqueles/as que "fazem a diferença" na educação escolar, produzindo modelos "ideais" de docentes que se afastam do que tem sido qualificado como educação tradicional.

Para construir as problematizações a respeito dos entrelaçamentos e os discursos pedagógicos de vertente crítica, é importante rememorar que críticas tecidas ao escolanovismo relacionaram-se com a intensificação de formas de mobilização popular que, no final da década de 1950 e início dos anos 1960, reivindicavam a constituição de uma "Escola Nova Popular" (SAVIANI, 2009). No Brasil, esse esforço teve como uma de suas figuras centrais o educador Paulo Freire, cujo ideário pedagógico libertador manteve muitos pontos em comum com o ideário da Escola Nova de tornar a educação agradável e capaz de despertar o interesse dos/as alunos/as para assumirem ativamente o trabalho escolar. Entretanto, a diferença desse pedagogo em relação ao movimento da Escola Nova consistiu em colocar a educação escolar a serviço dos interesses populares (SAVIANI, 2009). Essa abordagem da teoria crítica, portanto, recusa a transferência do conhecimento do/a professor/a para o/a aluno/a quando evita o verbalismo recorrente nas formas tradicionais de educar (SILVA, 2014).

Além de Freire, pode-se apontar Dermeval Saviani como outro importante educador alinhado à teoria crítica. Procurando orientar a prática educativa numa direção transformadora, no Brasil, na década de 1970, Saviani (2008a) formulou uma corrente pedagógica que ficou conhecida como pedagogia histórico-crítica. Vertente da teoria crítica que se firmou, fundamentalmente, a partir de 1979. Nessa formulação, a educação foi compreendida como inserida na prática social, que, por sua vez, é ponto de partida e ponto de chegada da prática educativa (SAVIANI, 2008a). Tópicos relevantes dessa abordagem pedagógica dizem respeito a considerar que o ponto inicial da atividade educativa não consiste na iniciativa isolada do/a professor/a ou do/a aluno/a, e sim, na ação conjunta que enfatiza e problematiza a prática social. Dessa forma, Saviani (2008b) reitera que a pedagogia histórico-crítica envolve a possibilidade de transformar a sociedade.

Os trabalhos desses autores podem ser compreendidos como integrantes de discursos educacionais que dizem ser dialéticos, críticos, progressistas, voltados à produção de um sujeito autônomo, livre e consciente. Esses discursos

\footnotetext{
1 A expressão "o cara" constitui-se em uma gíria brasileira usada para designar uma pessoa que se destaca em alguma atividade que desempenhe. Pode ser usada tanto para o gênero feminino quanto para o gênero masculino.
} 
educacionais estariam, portanto, bastante articulados com a produção de representações de bons/boas professores/as associadas com a possibilidade de promover a libertação dos/as educandos/as. Eles têm fornecido, como mostrou Garcia (2002), regras e conselhos que indicam como professores, professoras e outros sujeitos escolares devem ser e agir.

Porém, seus efeitos não se resumem aos clássicos espaços educativos, eles circulam, são ressignificados e transformados no que Paraíso (2007) nomeou como mídia educativa, termo que tem sido utilizado para referir os meios (televisão e revista) destinados explicitamente a educar pessoas a distância, em parceria ou em substituição à escola. Ao propor-se explicitamente a ensinar, a mídia educativa não abre mão de fazer o que ela já teria assumido como sua função e que diz respeito à veiculação de informações, à produção de desejos e ao estímulo de fantasias, por exemplo. A mídia educativa, dessa forma, midiatiza o currículo e a escola, alimenta-se de elementos do discurso pedagógico e pedagogiza a si mesma.

Entende-se, portanto, que há uma relação entre mídia e educação porque a mídia, além de divulgar, entreter, informar, também ensina cumprindo uma função educativa. Dizer isso implica considerar, como explicou Costa (2002), que diferentes textos culturais, tais como os programas de TV, acionam discursos que não apenas descrevem o que abordam, mas instituem as coisas e os entes do mundo. Assim, a linguagem e a cultura constituem o que é usualmente tomado como "realidade".

Dessa forma, é possível indicar que a mídia vem assumindo cada vez mais um forte papel pedagógico. Situação que permite argumentar que se exercem conjuntos de práticas discursivas que significam as relações sociais e que estas, por sua vez, entram no jogo das relações de poder. O que inclui considerar os modos como o discurso pedagógico opera regulando os sujeitos pedagógicos (DÍAZ, 1998).

Assim é importante indicar que os discursos educacionais acionados na mídia educativa têm colaborado para produzir um/a docente que assume cada vez mais a responsabilidade pela qualidade da educação. Por esse motivo, os/ as docentes que recebem destaque em um programa de TV, por exemplo, não são quaisquer profissionais que realizam um bom trabalho. Nem mesmo são, necessariamente, práticas novas que ganham visibilidade.

Como mostrou Ferreira (2015), os/as docentes e as práticas pedagógicas que tendem a merecer destaque e que extrapolam o âmbito escolar são aqueles/as que colocam ênfase no esforço pessoal (e até no sacrifício) para buscar superar quaisquer dificuldades em benefício de alunos/as e da qualidade da educação. Ou, ainda, são colocados em evidência professores/as que mais se inclinam a discursos que estão vigentes para além dos espaços educativos tradicionais.

Tendo em vista a atuação da mídia na constituição dos indivíduos do tempo em que se vive e, particularmente, de professores/as brasileiros/as, buscou-se, por meio dos estudos culturais de inspiração pós-estruturalista, problematizar alguns elementos dos discursos educacionais críticos acionados por professores/as participantes do quadro televisivo Meu professor é o cara. 
Embora seja possível argumentar que outros discursos educacionais são, também, acionados no referido programa de TV, restringiu-se a discussão produzida neste texto aos modos como os/as professores/as participantes do quadro Meu professor é o cara mobilizaram os discursos educacionais críticos nas situações apresentadas nesse programa.

\section{Caminhos metodológicos}

Para a produção do caminho metodológico deste estudo, buscou-se inspiração nas considerações de Paraíso (2012) a respeito dos modos de fazer pesquisas sob a perspectiva pós-estruturalista na área da Educação. Essas pesquisas não partem de um caminho pronto a ser percorrido, seguido e realizado. É possível realizar pesquisa em Educação sem ter um método, definido previamente, para ser seguido sem que novas elaborações metodológicas sejam realizadas (PARAÍSO, 2012). O que não significa que o estudo não irá contar com procedimentos metodológicos, e sim que tais procedimentos precisam ser elaborados ao longo do trabalho investigativo. Ou seja, para essas pesquisas não há um caminho pronto, há, isso sim, uma possibilidade de produzir um percurso metodológico à medida que se entra em contato com as discussões teóricas e atenta-se para uma temática a ser examinada.

Dessa forma, para viabilizar a construção da estratégia analítica, assistiu-se aos episódios de Meu professor é o cara no site $^{2}$ do programa, que disponibiliza todas as edições do quadro. Como esses episódios abordam uma gama ampla de temáticas, optou-se por fazer um recorte desse material, focalizando aqueles que tratavam do uso de recursos digitais/informáticos e lúdicos em sala de aula e nos quais os/as professores/as participantes acionaram enunciações dos discursos educacionais críticos. O que totalizou dez episódios que foram ao ar nas datas de 16, 23 e 30 de agosto de 2014; 11 de outubro de 2014; 6, 20 e 27 de dezembro de 2014; 31 de janeiro de 2015; e 7 e 28 de março de 2015.

Realizado o recorte e a seleção de material de pesquisa, passa-se à descrição dos episódios, atentando para a noção de discurso de Foucault e sua contribuição para investigações no campo educacional, compreendendo que

[...] a mídia, ao mesmo tempo que é um lugar de onde várias instituições e sujeitos falam - como veículo de divulgação e circulação dos discursos considerados "verdadeiros" em nossa sociedade -, também se impõe como criadora de um discurso próprio. Porém, pode-se dizer que, nela, talvez mais do que em outros campos, a marca da heterogeneidade, além de ser bastante acentuada, é quase definidora da formação discursiva em que se insere. Poderíamos dizer que hoje praticamente todos os discursos sofrem uma mediação ou um reprocessamento através dos meios de comunicação (FISCHER, 2001, p. 212).

${ }_{2}$ Disponível em: < http://redeglobo.globo.com/como-sera/meu-professor-e-o-cara/noticia/plantao.html\#5>. Acesso em: 21 mar. 2015. 
Discurso, segundo essa compreensão, é produtor dos objetos de que fala (FOUCAULT, 1997) e não um simples recurso para descrever o que lhe é exterior. Ou seja, trata-se de um termo que ajuda a enfatizar como o processo de construção do mundo social é linguístico (SILVA, 2000). Sendo assim, essa noção de discurso auxilia a elaboração das análises à medida que permite compreender que há produção de saberes apontados como "verdadeiros" e considerados "universais" e que, por sua vez, implicam hierarquias e classificações, regulando o que pode ser dito em cada tempo e lugar.

Esse argumento auxilia a compreender os discursos como práticas que instituem verdades, ou seja, como formas de articulação entre poder e saber. Quando, por exemplo, a mídia coloca em destaque um/uma professor/professora ou discursos considerados "verdadeiros", não o faz desinteressadamente, há relações de poder nessas situações. Nesse sentido, a

[...] verdade não existe fora do poder ou sem poder [...] é deste mundo; ela é produzida nele graças a múltiplas coerções e nele produz efeitos regulamentados de poder. Cada sociedade tem seu regime de verdade, sua "política geral" de verdade: isto é, os tipos de discurso que ela acolhe e faz funcionar como verdadeiros; os mecanismos e as instâncias que permitem distinguir os enunciados verdadeiros dos falsos, a maneira como se sanciona uns e outros; as técnicas e os procedimentos que são valorizados para a obtenção da verdade; o estatuto daqueles que têm o encargo de dizer o que funciona como verdadeiro (FOUCAULT, 2004, p. 12).

É importante mostrar que, nessa perspectiva, o poder não é tomado como algo que simplesmente diz não e interdita a ação, pois o que faz com que o poder circule e se mantenha é que ele "[...] produz coisas, induz ao prazer, forma saber, produz discurso" (FOUCAULT, 2004, p. 8). A partir do momento em que o poder foi considerado como articulado à produção de discursos, o problema deixou de

[...] fazer a partilha entre o que num discurso releva da cientificidade e da verdade e o que relevaria de outra coisa; mas de ver historicamente como se produzem os efeitos de verdade no interior de discursos que não são em si nem verdadeiros nem falsos (FOUCAULT, 2004, p. 7).

Isso indica que não há verdade fora do poder; as coisas ditas dependem do modo como poder e saber se articulam em cada tempo e lugar, através de diferentes discursos. Verdade aqui é entendida "[...] como produzida em conexão com o poder, como uma construção discursiva, como um efeito da articulação poder-saber" (PARAÍSO, 2007, p. 55-56). 
Ora, se o poder e a verdade estão circularmente ligados, se o poder opera em conexão com a verdade e esta só existe em relações de poder, então todos os discursos podem ser vistos como parte de uma luta para construir as próprias versões de verdade. Além disso, toda sociedade tem discursos aceitos como verdadeiros (PARAÍSO, 2007, p. 56).

Os discursos educacionais mais valorizados em um programa de TV, portanto, somente repercutem porque se inserem em uma ordem mais ampla de poderes e saberes. Díaz (1998), ao abordar discursos pedagógicos, explicou que o que é dito por um professor ou por uma professora se situa na ordem de um saber, não se constituindo em um dito autônomo e puramente individual. Por isso,

[...] não existe sujeito pedagógico fora do discurso pedagógico, nem fora dos processos que definem suas posições nos significados. A existência de um sujeito pedagógico não está ligada a vontades ou individualidades autônomas e livremente fundadoras de suas práticas. O sujeito pedagógico está constituído, é formado e regulado, no discurso pedagógico, pela ordem, pelas posições e diferenças que esse discurso estabelece. O sujeito pedagógico é uma função do discurso no interior da escola e, contemporaneamente, no interior das agências de controle (DÍAZ, 1998, p. 15).

Conforme Foucault (1988, p. 95), “[...] é justamente no discurso que vêm a se articular poder e saber”:

Os discursos, como os silêncios, nem são submetidos de uma vez por todas ao poder, nem opostos a ele. É preciso admitir um jogo complexo e instável em que o discurso pode ser, ao mesmo tempo, instrumento e efeito de poder, e também obstáculo, escora, ponto de resistência e ponto de partida de uma estratégia oposta. O discurso veicula e produz poder; reforça-o mas também o mina, expõe, debilita e permite barrá-lo (FOUCAULT, 1988, p. 96).

Dado o caráter do discurso como articulador de poder e saber, conforme Foucault, é através do discurso, portanto, que o poder-saber opera e circula numa sociedade como a nossa. E nesse sentido, o autor questiona:

[...] que tipo de poder é capaz de produzir discursos de verdade dotados de efeitos tão poderosos? Quero dizer que em uma sociedade como a nossa, mas no fundo em qualquer sociedade, existem relações de poder múltiplas que atravessam, caracterizam e constituem o corpo social e que estas relações de poder não podem se dissociar, se estabelecer nem funcionar sem uma produção, uma acumulação, uma circulação e um funcionamento do discurso. Não há possibilidade de exercício do poder sem uma certa economia dos 
discursos de verdade que funcione dentro e a partir desta dupla exigência. Somos submetidos pelo poder à produção da verdade e só podemos exercê-lo através da produção da verdade. Isto vale para qualquer sociedade, mas creio que na nossa as relações entre poder, direito e verdade se organizam de uma maneira especial (FOUCAULT, 2004, p. 170-180).

Há, portanto, um conjunto de regras que permitem que algo seja produzido como objeto de discursos, autorizando, também, a produção dos efeitos de verdade gerados pela articulação entre poderes e saberes.

\section{Problematizando os discursos de Meu professor é o cara}

Nesta seção, questionam-se importantes enunciações dos discursos educacionais de Meu professor é o cara. Estas enfatizam que a aprendizagem se efetiva a partir de certas configurações do espaço de sala de aula e dos investimentos docentes na afetividade. São enunciações que acionam elementos dos discursos educacionais críticos, mas não o fazem sem transformá-los. É importante ressaltar que esses discursos oriundos da literatura pedagógica acabam sendo deslocados de forma particular pela mídia educativa, uma vez que a TV seleciona e utiliza desses discursos educacionais apenas o que lhe interessa. Dessa forma, a televisão reprocessa esses discursos para tornar possível a valorização de aspectos da teoria crítica que fazem referência a uma prática docente diferenciada. Uma prática propositora de mudança, com foco no interesse e na aprendizagem dos/as estudantes que fecham com os propósitos midiáticos de atribuir ao/à professor/a a gigantesca tarefa de "salvar" a educação através de grandes esforços pessoais.

Em diversos episódios do programa analisado, os/as professores/as participantes do quadro referem que sua prática docente pressupõe uma modificação da sala de aula para afastar-se ao máximo do ensino tradicional. Isto é, para diferenciar a sala de aula daquela que mantinha uma classe atrás da outra, formando fileiras e que colocava a mesa do/a professor/a em posição privilegiada para o controle dos/as estudantes. Tal esforço é apresentado como necessário à realização de trabalhos em grupo ou atividades em que foram utilizados recursos lúdicos e digitais/ informáticos. Atividades que são especialmente valorizadas na mídia educativa.

Em dois episódios ${ }^{3}$, as salas de aula que inicialmente possuíam classes dispostas em fileiras foram modificadas para a realização de atividades que envolviam o uso do vídeo e dos jogos, respectivamente. No primeiro caso, os/ as estudantes foram dispostos/as em uma configuração que sugere que eles/as escolheram onde queriam sentar e, no segundo caso, a configuração da sala implicou a colocação de quatro classes juntas para a realização de trabalho

3 Episódios exibidos em 30 de agosto e 11 de outubro de 2014. 
em grupos. Em outros dois episódios ${ }^{4}$, as classes também apareceram dispostas uma atrás da outra, num primeiro momento, porém, quando foram realizadas as atividades de jogo, os/as estudantes apareceram dispostos/as em outra configuração que propiciou o trabalho em duplas.

Não foram mostradas classes dispostas em fileiras em quatro episódios ${ }^{5}$, nos quais aparece a organização da sala de aula em duplas para um jogo de $\mathrm{RPG}^{6}$, em pequenos grupos e em formato circular para diferentes atividades. Ao ser entrevistada, uma das professoras destacadas no programa de TV aborda sua preferência pela disposição das classes dos/as estudantes em círculo:

Eu gosto de sentar a minha turma não em fileiras, mas em círculo, para que todos possam se ver, ver a professora e fazer aquela leitura gradativa, aquela leitura individual ou a leitura oral em grupo. Eu gosto de ler para eles porque, se eles vêem que a professora gosta de ler, que ela lê para eles, eles vão ter o prazer de ler para a professora também ${ }^{7}$.

Já um professor entrevistado ressaltou:

I As atividades são diversas. Pra trabalhar a questão fonética, a gente tem o circuito que é a grande atividade que eles gostam porque a gente sai do espaço comum que é a sala de aula ${ }^{8}$.

Discutindo o modo como as pedagogias articulam poderes e saberes para disciplinar os corpos, Gore (1994) aborda a disposição das classes escolares em círculo nas práticas pedagógicas que buscam ser progressistas e emancipatórias como forma de contrapor-se à sala de aula tradicional (aquela em que a posição de todos/as é fixa, em fileiras perfeitamente alinhadas, para possibilitar a vigilância constante). Assumir a posição de modificar a disposição da sala de aula como forma de contrapor-se ao ensino tradicional parte do pressuposto de que o círculo

[...] abre a possibilidade de que todo estudante manifeste sua opinião e de que seja ouvido. Com as estudantes sentando no chão ou em cadeiras móveis, elas são libertadas dos limites restritivos de suas carteiras, onde ficam separadas entre si (GORE, 1994, p. 15).

\footnotetext{
4 Episódios exibidos em 20 de dezembro de 2014 e 7 de março de 2015.

5 Episódios exibidos em 23 de agosto de 2014, 6 de dezembro de 2014, 31 de janeiro de 2015 e 28 de março de 2015.

${ }_{6}$ RPG - Role-playing game.

7 Professora destacada no episódio exibido em 6 de dezembro de 2014.

8 Professor destacado no episódio exibido em 27 de dezembro de 2014.
} 
Essa "libertação" dos limites restritivos relativos à disposição da sala de aula vai ao encontro das propostas decorrentes dos discursos educacionais que reelaboraram o movimento da Escola Nova. As carteiras parafusadas no solo eram consideradas inimigas dos movimentos de reforma que viam na disposição da sala de aula um importante potencial para mudar as práticas pedagógicas (DUSSEL, CARUSO, 2003).

Porém, não existe nada inerentemente libertador nessa prática, pois, por um lado,

[...] o círculo pode exigir das estudantes uma maior autodisciplina, pela qual elas assumem a responsabilidade por comportar-se "apropriadamente" sem o "olhar" da professora. Por outro lado, a privacidade parcial permitida pela colocação tradicional de carteiras, na qual se está sob a vigilância ou supervisão principalmente da professora, pode desaparecer à medida que as estudantes ficam cada vez mais diretamente também sob a supervisão de suas colegas. A estudante que prefere não se manifestar fica menos evidente quando todas as carteiras estão voltadas para a frente da sala de aula, assim como a estudante que não pode usar sapatos novos, que fica ruborizada, que está entediada e assim por diante (GORE, 1994, p. 15).

E, nesse sentido, é importante destacar que, para a perspectiva teórica assumida nesse texto, a pedagogia crítica, mesmo voltada para a mudança, transformação e libertação dos indivíduos, também está envolvida em relações de poder. A diferença, porém, consiste na compreensão que se tem de poder:

O poder que o educador crítico ou a educadora libertadora exercem sobre os seus e as suas aprendizes na situação de ensino crítico, ao universalizarem uma forma particular de compreender a história e seu desenvolvimento, aparece como um aspecto negativo e contraditório em relação a uma ética de liberdade defendida e proposta por esses discursos. O poder é uma propriedade essencialmente negativa. É uma forma de opressão que atua de modo vertical e descendente e tem origem na posse da riqueza econômica, do capital cultural ou na posição que se ocupa no aparelho de Estado (GARCIA, 2002, p. 92).

Se for realizada uma reflexão que se afasta da noção de que o poder distorce ou mistifica uma suposta verdade, reprime e interdita ações dos indivíduos e se for considerado que o poder é produtivo e que possibilita compreender que todos são regulados e controlados por forças mais difusas na sociedade contemporânea, será possível considerar que há mecanismos de regulação e controle nas práticas pedagógicas alinhadas à teoria crítica. Mesmo que estes estejam dispersos em diversas situações que se configuram como libertadoras. Isso porque, para Silva (1994, p. 252), “[...] nenhum dispositivo, nem mesmo os críticos, tal como as pedagogias críticas, estão absolvidos de envolvimento 
em relações de poder, regulação e governo". Aliás, conforme Foucault (1995), “[...] é necessário que haja liberdade para que o poder se exerça" (FOUCAULT, 1995, p. 244).

Nesse sentido, Sommer (2007) explica que o deslocamento das classes, dispondo-as em círculo,

[...] pode implicar maior controle, uma vez que se amplia o campo de visibilidade e de vigilância dos alunos. Quer dizer, se na sala de aula organizada em fileiras, em tese, cada aluno é supervisionado apenas pela professora, existindo um espaço de invisibilidade, ao menos parcial, que se concretiza no esconder-se atrás do colega sentado na frente, na disposição por círculo todos são sempre visíveis, alcançáveis pelo olhar da professora e pelo olhar de cada um dos colegas (SOMMER, 2007, p. 63-64).

Por esse motivo, quando professores/as utilizam a disposição do círculo em sala de aula, por mais que pareça libertadora, não é possível deixar de considerar que essa prática está gerando um controle normativo ${ }^{9}$ por parte de todos sobre cada um. Portanto, práticas consideradas alternativas ao fazer tradicional, como as observadas em $\mathrm{Meu}$ professor é o cara, relativamente às mudanças na configuração da sala de aula, não estão isentas de processos de regulação e normalização de condutas.

Não se busca com isso argumentar a favor do retorno do uso de fileiras à moda das salas de aula tradicionais, mesmo reconhecendo que não é possível atribuir à configuração da sala de aula em círculo alguma garantia de libertação. Está se indicando que não há efeitos garantidos nas práticas educacionais supostamente libertadoras porque em qualquer um desses casos há regulação de condutas dos sujeitos escolares. Ou, ainda, ressalta-se que o uso do círculo como disposição da sala de aula inscreve a atividade pedagógica em uma forma sutil e econômica de ação do poder que faz parecer que, mesmo estando em uma sala de aula, não se perceba estar em uma.

Outra importante enunciação que chamou nossa atenção nos episódios de Meu professor é o cara diz respeito à necessidade de os/as professores/as investirem na afetividade em sua atividade profissional. Pois o afeto tem sido compreendido como "[...] facilitador da aprendizagem discente, ou ainda mais, como um fator indispensável para que a mesma ocorra" (VARGAS, CARVALHO, 2012, p. 115), como um elemento sem o qual a aprendizagem ficaria fortemente prejudicada. Professores/as destacados/as nos episódios de Meu professor é o cara apontam a afetividade e a interação como fundamental no processo educativo, tal como se pode depreender dos seguintes excertos:

9 Um controle normativo acontece quando se realizam julgamentos que comparam o que está e o que não está de acordo com alguma norma que não é produzida com base na ideia de retidão, mas, isto sim, na existência de uma média (EWALD, 1993). 
Essa minha relação com os alunos é bacana, eles me seguem nas redes sociais, eu faço parte da vida deles, eu quero saber o que eles estão lendo, eu quero saber o que eles estão jogando pra que eles vejam que a gente não é diferente, a gente ta ali, nós somos parceiros nesse processo ${ }^{10}$.

Tudo que venha a agregar para o aprendizado deles, eu sou uma pessoa muito aberta ${ }^{11}$.

Eu procuro muito me aproximar, eu sempre me coloco ao lado deles como uma parceira ${ }^{12}$.

Eu acredito nas relações afetivas, e esses alunos buscam ainda na figura do professor a afetividade ${ }^{13}$.

Nesses excertos, os/as professores/as apontam a afetividade e a interação como formas de criar condições para a aprendizagem. O que ocorre na medida em que se estabelecem não apenas atitudes de carinho e receptividade, mas também quando se produzem parcerias relativamente às atividades escolares e quando se evitam posições de superioridade em relação aos/às estudantes. Trata-se de uma abordagem pedagógica elaborada a partir da compreensão de que as necessidades e os campos de interesse dos alunos precisam estar na base dos programas escolares (GAUTHIER, 2014).

Porém,

[...] embora essa alegria, emoção, harmonia e esse afeto aparentem inocência e desinteresse, estas podem ser as formas pedagógicas pelas quais o projeto da mídia busca conquistar o apoio popular; as estratégias utilizadas para controlar e governar as pessoas de modo a que passemos a operar com sua lógica; de modo a que nossas condutas sejam governadas e conduzidas por técnicas e estratégias suaves, afetuosas e amorosas (PARAÍSO, 2001, p. 151).

Por esse motivo, o apelo ao afeto suscita, a partir de uma perspectiva pós-estruturalista, que sejam realizadas algumas problematizações. Em uma concepção tradicional, interpretava-se a aprendizagem a partir da transmissão do conhecimento, aquele que sabia ensinava quem não sabia e, portanto,

\footnotetext{
${ }^{10}$ Professora destacada no episódio exibido em 16 de agosto de 2014.

${ }^{11}$ Professora destacada no episódio exibido em 11 de outubro de 2014.

12 Professora destacada no episódio exibido em 11 de outubro de 2014.

13 Professor destacado no episódio exibido em 27 de dezembro de 2014.
} 
[...] o aluno era visto como um sujeito passivo e ao professor cabia o controle das condições de ensino: é o tipo de ensino que Paulo Freire denunciava como "bancário". Atualmente, as concepções dominantes são bem diferentes: entende-se que a aprendizagem ocorre a partir da relação entre o sujeito e os diversos objetos de conhecimento, sendo, no entanto, tal relação sempre mediada por algum agente cultural (LEITE, 2011, p. 18).

Os argumentos apontados acima, relativamente à necessidade da afetividade como elemento de mediação da relação pedagógica, direcionam o foco "[...] na determinação da natureza das relações que se estabelecem entre os sujeitos (alunos) e os demais objetos de conhecimento (áreas e conteúdos escolares)” (LEITE, 2011, p. 24). Estes implicam, também, a produção de docentes que assumem uma visão romântica em relação ao seu trabalho, pois

[...] são levadas/os a acreditarem que aquela/e que dá e recebe afetos, que se emociona com uma causa e que se preocupa com o destino do outro não terá qualquer dificuldade para exercer bem a sua profissão. Essa é uma prática constituída por técnicas ligadas aos sentimentos que se encontram em cada uma/um de nós. Só é necessário deixar esses sentimentos aflorarem. É isso que na mídia educativa se faz de diferentes maneiras: incentivar, convocar e seduzir para que esses sentimentos sejam exteriorizados pela/o docente (PARAÍSO, 2006, p. 106).

A partir do exposto, é possível argumentar que a atenção voltada ao/à estudante começa a desenvolver-se, portanto, a partir dos preceitos propostos no movimento da Escola Nova, em que houve o deslocamento do foco para o aluno, valorizando-se a relação professor-aluno na prática educativa (SAVIANI, 2013). Um aspecto que continua a se fazer presente em discursos educacionais de vertente crítica.

Na perspectiva crítica, Freire (2011, p. 138), ao abordar a necessidade da interação e afetividade entre estudantes e professores/as, explica que é necessário "[...] estar aberto ao gosto de querer bem, às vezes, à coragem de querer bem aos educandos e à própria prática educativa de que participo”. Portanto, para a teoria crítica,

[...] a qualidade das interações que ocorrem em sala de aula, incluindo todas as decisões de ensino assumidas, refere-se a relações intensas entre professores e alunos, proporcionando diversificadas experiências de aprendizagem, a fim de promover o desenvolvimento dos alunos (LEITE, 2011, p. 42).

Esses/as professores/as, ao colocarem as relações afetivas como necessárias ao bom trabalho docente, estariam, portanto, acionando o que os discursos educacionais críticos preconizam ao enfatizar que a relação entre docentes e estudantes deve ser pautada na afetividade e na alegria, através de um olhar interessado, de uma abertura ao querer 
bem o/a estudante. Aliás, pergunta Freire (2011, p. 66), como educar “[...] se não desenvolvo em mim a indispensável amorosidade aos educandos com quem me comprometo e ao próprio processo formador de que sou parte?". Trata-se de uma forma de compreender que as relações afetivas entre professores/as e alunos/as são importantes para que se estabeleça um processo democrático.

A perspectiva crítica, mesmo com sua busca em produzir indivíduos participativos, críticos, autônomos e reflexivos, está implicada em relações de poder, porque a "liberdade" alcançada é aquela em que as normas necessárias ao próprio processo democrático são interiorizadas e atuam de forma muito sutil e difícil de visualizar. Essa postura seria uma forma de vigilância e de coerções individuais e coletivas discretas que acionam "[...] uma forma de poder cujo objetivo final é assegurar a salvação individual no outro mundo" (FOUCAULT, 1995, p. 237), denominada de poder pastoral. Contudo, esse tipo de poder que foi associado a uma instituição religiosa definida ampliou-se para um âmbito muito maior.

Dessa forma, aspectos que compõem os discursos educacionais críticos foram recuperados de Sócrates e Platão pelo cristianismo e, mais tarde, laicizaram-se. Por esse motivo, a relação pedagógico-crítica realiza a condução de sujeitos estabelecendo uma relação "[...] do tipo pastoral-disciplinar que, agindo de modo calculado e racional, e em nome da verdade e da emancipação, pretende modelar a consciência e a conduta dos sujeitos sobre os quais atua" (GARCIA, 2002, p. 130-131).

Pensando na escola, mais precisamente na atividade docente, muitas vezes esta é associada a modos de conduzir a si e aos outros e a aspectos de salvação da educação. Professores/as são posicionados/as a assumirem funções pastorais, que implicam uma "[...] dedicação incansável, uma entrega inabalável à profissão e ao outro" (PARAÍSO, 2007, p. 173):

Trata-se de mobilizar, sensibilizar e conscientizar as docentes da importância do seu uso na profissão e dos resultados que esse uso pode ter na sua auto-realização e na melhoria da qualidade do ensino (PARAÍSO, 2007, p. 176).

A função do/a docente crítico/a seria, portanto, de acordo com Garcia (2002, p. 146), a de "[...] exercer uma forma de pastorado da consciência crítica e engajada, acompanhando com dedicação e atenção cada indivíduo em particular e todos rumo a uma existência racional e moral superior". O que implica, em especial, formas sutis, discretas e refinadas de exercício do poder que visam a administrar a liberdade dos indivíduos, uma vez que, conforme Foucault (2008), o poder pastoral se transformou significativamente com o passar dos séculos sem nunca ser verdadeiramente abolido.

Educação Por Escrito, Porto Alegre, v. 9, n. 1, p. 23-40, jan.-jun. 2018 
Por esse motivo, a ação docente é vista nos discursos críticos como uma tarefa implicada na produção de indivíduos conscientes, transformadores e emancipados, que, ao mesmo tempo,

[...] implementam uma tecnologia pedagógica, na formação e no treinamento docente, que privilegia as práticas de si e as práticas exemplares introduzindo aprendizes do magistério e do trabalho pedagógico nas artes da "boa" consciência e da autodeterminação, de modo a produzi-los enquanto sujeitos de princípios e engajados (GARCIA, 2002, p. 141-142).

Além disso, o/a docente que desenvolve uma prática educativa crítica e dialógica, ao realizar sua tarefa pastoraldisciplinar, é apontado/a como alguém que deveria possuir habilidades de relacionamento baseadas no carisma. Por isso, é frequente a afirmação de que é necessário que esses/as docentes sejam "amorosos/as", "humildes" e que tenham "fé" e "esperança" nos homens.

Isso porque

[...] desde o final do século XIX, e especialmente na pedagogia contemporânea, a definição da relação pastoral pedagógica em termos tais como compreensão, democracia, interesses, necessidades, liberdade, autonomia, amor, diálogo e a abertura do docente às experiências e aos sentimentos dos estudantes, têm crescentemente "eticalizado" o exercício do poder e da autoridade nas instituições pedagógicas, escolares, etc. As formas de regulação implementadas pela pedagogia e pela didática não mais puderam prescindir de aspectos relacionados às características socioemocionais e culturais dos indivíduos (GARCIA, 2002, p. 163).

A mídia educativa utiliza e divulga, portanto, esse discurso sobre o/a professor/a que se dedica, que se doa, que faz tudo com amor em prol dos/as estudantes, contribuindo assim para a educação como um todo. De acordo com Fischer (2001, p. 204), "[...] quando a televisão, por exemplo, se apropria do discurso missionário do professor, fala e faz falar esse discurso, fala e faz falar um discurso segundo algumas de suas regras".

Nos discursos educacionais da mídia educativa, é possível identificar, portanto, a forma sutil como o poder circula, já que são utilizadas estratégias de subjetivação que buscam professores/as de determinados tipos. De acordo com Paraíso (2007), o poder entendido como uma ação sobre ações é

[...] exercido no discurso da mídia educativa, agindo sobre a ação das docentes e acionando estratégias e técnicas que permitam que ela aja sobre si mesma, possibilitando não somente o esclarecimento da professora, mas também a sua ação sobre a sua conduta. O objetivo é tornar-se uma docente melhor, uma pessoa melhor e, consequentemente contribuir para a construção de um país melhor (PARAÍSO, 2007, p. 179). 
Enfim, quando práticas docentes que compreendem elementos da teoria educacional crítica são valorizadas em um programa de TV, como ocorre em Meu professor é o cara, no qual a inovação, a criatividade e a possibilidade de fazer a diferença são enfatizadas na busca da mudança e da transformação, não é possível afirmar que há isenção de relações de poder, embora tudo aparente sua ausência.

Como explicou Lewkowicz (2010), também existem formas de controle em situações que parecem inocentes e que não configuram imposições. Uma forma de controle acaba funcionando porque tais situações estimulam os/as estudantes a exercerem controles sobre si mesmos. Desde essa perspectiva, cabe ao/a professor/a observar e acompanhar cuidadosa e amorosamente os/as seus/suas alunos/as para que todos/as desloquem a si mesmos em direção à conscientização e à liberdade. $\mathrm{O} / \mathrm{a}$ mestre assume, portanto, a tarefa de ser um guia das consciências que não age de forma arrogante e autoritária, colocando-se de forma que tanto ele/a quanto os/as estudantes sejam educadores e educandos (FREIRE, 2011). Para que isso seja possível, os/as docentes precisam tornar-se parceiros/as de seus/ suas alunos/as, produzindo a abertura necessária para facilitar a comunicação e garantir a adesão dos/as estudantes na tarefa relativa ao esclarecimento e na mudança de si mesmos para formas de vida melhores e mais justas. Ou, ainda, é possível dizer que a tarefa docente está relacionada à produção de envolvimento entre professores/as e alunos/as, visando a alguma forma de libertação. Enfim, a ênfase na afetividade e na interação entre docentes e discentes pode ser uma forma de produzir as condições necessárias para que o poder pastoral se exerça.

\section{Considerações finais}

É possível dizer sobre Meu professor é o cara o mesmo que foi dito em relação a outros produtos da mídia educativa: estes acionam estratégias que seduzem porque identificam seus objetivos com desejos, anseios, bem como com vontades de transformação de diferentes indivíduos.

A mídia educativa, e mais especificamente o quadro do programa de TV analisado, acaba acionando apenas alguns desses elementos, produzindo uma ênfase específica que depende dos indivíduos para os quais o discurso é endereçado (PARAÍSO, 2007). Assim, verifica-se que o discurso educacional da mídia ao selecionar parte de elementos de discursos oriundos da literatura pedagógica está imbricado em relações de poder-saber, pois reforça e divulga estratégias que contribuem para alinhar os discursos pedagógicos a desejos de mudança, bem como ao fazer prático. Estratégias essas que produzem sujeitos que, em especial, acreditam que podem atuar na mudança das escolas públicas brasileiras.

Por isso, os discursos educacionais acionados no programa de TV apontaram para a reorganização do espaço da sala de aula, saindo do aspecto tradicional de fileiras para disposição das classes, formando círculos ou outras 
configurações que possibilitassem a formação de duplas ou grupos. A reorganização das classes aconteceu quando foram realizadas atividades que faziam uso de recursos didáticos lúdicos e/ou associados a recursos digitais/ informáticos, implicando uma organização dos/as estudantes de modo a favorecer a atividade coletiva. Além disso, as atividades que utilizaram recursos digitais/informáticos, tal como projetores e vídeos, também dispuseram os/as estudantes de maneira diversa do enfileiramento tradicional. Com relação a tal ponto, cabe salientar que este, embora a modificação nos espaços de aprendizagem aparente falta ou redução de regulação e condução dos sujeitos, por tratar-se de um modo alternativo e diferente de se promover a aprendizagem, não está isento de relações de poder.

Além disso, os/as professores/as destacados/as no programa ressaltam em suas falas a necessidade da afetividade como elemento de seu trabalho. Um aspecto fortemente associado com as reconfigurações que o poder pastoral tem sofrido para produzir formas de direcionar condutas de forma sutil.

Enfim, Meu professor é o cara identifica suas metas com os desejos docentes de buscar “libertar" os/as alunos/as dos poderes que os/as oprimem, sensibilizando-os para a construção de conhecimentos que possam ajudar a melhorar o mundo. Meu professor é o cara identifica suas metas com os desejos docentes de ver seu digno trabalho reconhecido amplamente (FERREIRA, 2015), através de práticas de homenagens que incluem a publicização midiática da atividade daquele/a professor/a. Afora isso, é interessante pontuar que essas estratégias midiáticas podem funcionar como forma de captura dos discursos vigentes de outros/as docentes e sujeitos escolares, possibilitando uma importante expansão da ação de tais discursos.

Mas Meu professor é o cara também inscreve a todos/as em discursos educacionais midiáticos tão articuladores de poderes e saberes quanto quaisquer outros. Insere os sujeitos escolares em poderes sutis e eficazes justamente porque estão pautados em saberes. Lança seus públicos em enunciações que se pautam nas sutilezas das articulações entre poderes e saberes que tornam possível rearticular tais enunciações de muitas diferentes formas. Por esse motivo, os/as professores/as destacados/as no quadro não foram qualquer um/a, mas aqueles/as que estavam na ordem desses discursos, já que o próprio quadro objetivava mostrar atitudes que a mídia educativa julga alinhadas à mudança na sociedade e ao interesse dos/as estudantes.

\section{Referências}

COSTA, Marisa. Ensinando a dividir o mundo; as perversas lições de um programa de televisão. Revista Brasileira de Educação, n. 20, p. 71-82, maio-ago. 2002.

DÍAZ, Mario. Foucault, docentes e discursos pedagógicos. In: SILVA, Tomaz (Org.). Liberdades reguladas: a pedagogia construtivista e outras formas de governo do eu. Petrópolis: Vozes, 1998. p. 14-29. 
DUSSEL, Inés; CARUSO, Marcelo. A invenção da sala de aula: uma genealogia das formas de ensinar. São Paulo: Moderna, 2003. EWALD, François. Foucault, a norma e o direito. Lisboa, Vega, 1993.

FERREIRA, Maurício. Espetacularização da carreira docente: prêmio professores do Brasil como prática da economia da educação. Porto Alegre, 2015. 243 f. Tese (Doutorado em Educação) - Programa de Pós-Graduação em Educação, Faculdade de Educação, Universidade Federal do Rio Grande do Sul, Porto Alegre, 2015.

FISCHER, Rosa. Foucault e a análise do discurso em educação. Cadernos de Pesquisa, n. 114, p. 197-223, 2001.

FOUCAULT, Michel. A arqueologia do saber. Rio de Janeiro: Forense Universitária, 1997.

FOUCAULT, Michel. História da sexualidade I: a vontade de saber. Rio de Janeiro: Edições Graal, 1988.

FOUCAULT, Michel. Microfísica do poder. 25. ed. São Paulo: Graal, 2004.

FOUCAULT, Michel. O sujeito e o poder. In: DREYFUS, Hubert; RABINOW, Paul. Michel Foucault, uma trajetória filosófica: para além do estruturalismo e da hermenêutica. Rio de Janeiro. Forense Universitária, 1995. p. 231-249.

FOUCAULT, Michel. Segurança, território, população. Curso no Collège de France (1977-1978). São Paulo: Martins Fontes, 2008. FREIRE, Paulo. Pedagogia da autonomia: saberes necessários à prática educativa. 43. ed. São Paulo, Paz e Terra, 2011.

GARCIA, Maria Manuela Alves. Pedagogias críticas e subjetivação. Uma perspectiva foucaultiana. Petrópolis: Vozes, 2002.

GAUTHIER, Clermont. Da pedagogia tradicional à pedagogia nova. In: GAUTHIER, Clermont; TARDIF, Maurice (Org.). A pedagogia: teorias e práticas da antiguidade aos nossos dias. Petrópolis: Vozes, 2014. p. 153-177.

GORE, Jennifer. Michel Foucault e educação: fascinantes desafios. In: SILVA, Tomaz T. (Org.). O sujeito da educação: estudos foucaultianos. Petrópolis: Vozes, 1994. p. 9-20.

LEITE, Sérgio (Org.). Afetividade e práticas pedagógicas. São Paulo: Casa do Psicólogo, 2011. Disponível em: <http://ifsul.bv3. digitalpages.com.br/users/publications/9788573964493/pages/-1>. Acesso em: 16 out. 2016.

LEWKOWICZ, Ignacio. Escuela y ciudadanía. In: COREA, Cristina; LEWKOWICZ, Ignacio. Pedagogía del aburrido: escuelas destituidas, familias perplejas. Buenos Aires: Editorial Paidós, 2010. p. 19-40.

PARAÍSO, Marlucy. A produção do currículo na televisão: que discurso é esse? Educação \& Realidade, Porto Alegre, v. 26, n. 1, p. 141-160, 2001.

PARAÍSO, Marlucy. Currículo e mídia educativa brasileira: poder, saber e subjetivação. Chapecó: Argos, 2007.

PARAÍSO, Marlucy. Metodologias de pesquisas pós-críticas em educação e currículo: trajetórias, pressupostos, procedimentos e estratégias analíticas. In: MEYER, Dagmar; PARAÍSO, Marlucy (Org.). Metodologias de pesquisas pós-críticas em educação. Belo Horizonte: Mazza Edições, 2012. p. 23-45.

PARAÍSO, Marlucy. Política da subjetividade docente no currículo da mídia educativa brasileira. Educação e Sociedade, v. 27, n. 94, p. 91-115, jan.-abr. 2006.

SAVIANI, Dermeval. A pedagogia no Brasil: história e teoria. Campinas: Autores Associados, $2008 \mathrm{a}$. 
SAVIANI, Dermeval. Pedagogia histórico-crítica: primeiras aproximações. 10. ed. Campinas: Autores Associados, 2008b.

SAVIANI, Dermeval. Escola e democracia: teorias da educação, curvatura da vara, onze teses sobre a educação política. 41. ed. Campinas: Autores Associados, 2009.

SAVIANI, Dermeval. História das ideias pedagógicas no Brasil. 4. ed. Campinas: Autores Associados, 2013.

SILVA, Tomaz. Documentos de identidade. Uma introdução às teorias do currículo. 3. ed. Belo Horizonte: Autêntica, 2014.

SILVA, Tomaz. Teoria cultural e educação: um vocabulário crítico. Belo Horizonte: Autêntica, 2000.

SILVA, Tomaz. O adeus às metanarrativas educacionais. In: SILVA, Tomaz Tadeu da (Org.). O sujeito da educação: estudos foucaultianos. Petrópolis: Vozes, 1994. p. 247-258.

SOMMER, Luis Henrique. A ordem do discurso escolar. Revista Brasileira de Educação, v. 12, n. 34, p. 57-67, jan.-abr. 2007.

VARGAS, Juliana; CARVALHO, Rodrigo. Discursos sobre afetos docentes: uma ortopedia de gênero? Revista Espaço Acadêmico, n. 129, p. 11-117, 2012.

Recebido em: outubro/2017

Aceito em: abril/2018

\section{Endereço para correspondência:}

Ana Paula Quevedo Peil <angela.bicca@hotmail.com>

Instituto Federal Sul-rio-grandense - IFSUL

Rua Pinto Martins 271 apto 204

CEP ??, Pelotas, RS, Brasil 